\title{
The COVID-19 Pandemic and Its Implications for Rural Economies
}

\author{
Jeremy Phillipson ${ }^{1, *}$, Matthew Gorton ${ }^{1}$, Roger Turner ${ }^{1}$, Mark Shucksmith ${ }^{1}$, \\ Katie Aitken-McDermott ${ }^{1}$, Francisco Areal ${ }^{1}{ }^{1}$, Paul Cowie ${ }^{1}$, Carmen Hubbard ${ }^{1}$, Sara Maioli ${ }^{1}$, \\ Ruth McAreavey ${ }^{1}{ }^{(\mathbb{D},}$ Diogo Souza-Monteiro ${ }^{1}$ (i), Robert Newbery ${ }^{2}$, Luca Panzone ${ }^{1}$, \\ Frances Rowe ${ }^{1}$ and Sally Shortall ${ }^{1}$ \\ 1 Centre for Rural Economy Newcastle University, Newcastle upon Tyne NE1 7RU, UK; \\ matthew.gorton@ncl.ac.uk (M.G.); turners20@btinternet.com (R.T.); mark.shucksmith@ncl.ac.uk (M.S.); \\ k.m.aitken-mcdermott@newcastle.ac.uk (K.A.-M.); francisco.areal-borrego@newcastle.ac.uk (F.A.); \\ paul.cowie@newcastle.ac.uk (P.C.); carmen.hubbard@ncl.ac.uk (C.H.); sara.maioli@ncl.ac.uk (S.M.); \\ Ruth.McAreavey@newcastle.ac.uk (R.M.); diogo.souza-monteiro@ncl.ac.uk (D.S.-M.); \\ luca.panzone@ncl.ac.uk (L.P.); frances.rowe@ncl.ac.uk (F.R.); sally.shortall@ncl.ac.uk (S.S.) \\ 2 Newcastle Business School, Northumbria University, Newcastle upon Tyne NE1 8ST, UK; \\ robert.newbery@northumbria.ac.uk \\ * Correspondence: jeremy.phillipson@ncl.ac.uk
}

Received: 9 April 2020; Accepted: 8 May 2020; Published: 12 May 2020

\begin{abstract}
This paper presents a rapid assessment of current and likely future impacts of the COVID-19 outbreak on rural economies given their socio-economic characteristics. Drawing principally on current evidence for the UK, as well as lessons from the 2001 Foot and Mouth Disease outbreak and the 2007/8 financial crises, it outlines the likely key demand and supply effects, paying attention to the situation for agriculture as well as discussing the implications for rural communities. A distinction is made between the effects on businesses offering goods and services for out-of-home as opposed to in-home consumption. Gendered dimensions are also noted as likely business and household strategies for coping and adaptation. The paper concludes with a brief mapping of a research agenda for studying the longer-term effects of COVID-19 on rural economies.
\end{abstract}

Keywords: COVID-19; rural economies; resilience; rural businesses

\section{Introduction}

The COVID-19 outbreak and government-led measures to contain it are having widespread effects on rural economies across Europe. This disease is affecting all aspects of rural society, both directly when people from rural communities fall ill, but also because of the social distancing restrictions that are in place to limit the progress of the disease. It is affecting household incomes and rural businesses in every sector of Europe's diverse rural economies, as well as charitable and community organisations. Some of these impacts will also be medium- or long-term.

Past crises have highlighted the resilience and adaptability of rural economies. The Foot and Mouth Disease (FMD) outbreak in 2001 and the associated rural shutdown in the UK [1] illustrated this, as did the more recent recovery from the 2007/8 financial crisis and recession [2]. Some of the structural features of rural areas, notably their more dispersed population base and their already established tradition of home-based working [3] may act as a source of resilience during this crisis. However, more severe restrictions placed on personal travel for non-essential purposes may impact more heavily on rural areas, due to the greater dispersal of workplaces, consumer and business services, and the importance of visitor economies to many rural areas [4]. Thus, there is a need to avoid overgeneralising 
spatial impacts or assuming that their resilience means rural communities can be left to fend for themselves in order to weather crises, or that their resilient behaviour itself does not have unintended effects. Capacities to withstand and adapt to periods of hardship and crisis are highly variable both between and within communities [5] and among different firms and sectors [6,7].

This paper provides a rapid assessment of the current and likely future impacts of the COVID-19 outbreak on rural economies, given their socio-economic characteristics. The primary focus is on the UK situation, but the issues raised have resonance for rural economies in the EU, which face similar issues.

\section{The Demand and Supply Side Effects of COVID-19}

Businesses and sectors are being impacted in several ways. Demand and supply side effects have significant knock on impacts on all sectors, with a decline in any one firm's turnover having reverberations for linked and allied businesses and their associated households.

On the demand side, we can roughly divide effects into: goods and services consumed in the home (meals cooked at home, television subscription packages, domestic heating, etc.), goods and services consumed out of the home (cafés, restaurants, hotels and hospitality, bars, leisure centres, gyms, soft plays, museums, countryside attractions, public transport, educational facilities, theatres and arts venues, etc.), and goods and services traded between businesses. The immediate economic impact during the disease diffusion phase will be greatest for those firms (and their supply chains) unable to provide their produce or services to personal or business consumers other than within their own business premises.

Out-of-home consumption is currently being affected the most, with businesses in this market facing acute cash flow issues and staff layoffs [8], either directly when they serve final consumers or indirectly because they supply other businesses geared to out-of-home consumption. The immediate impact on local rural economies will therefore depend on their composition between goods and services geared to in-home and out-of-home consumption and the degree to which businesses can reorient their operations from the latter to the former (for example, a restaurant offering home delivery).

Regarding goods and services consumed in the home, there will be both substitution (positive) and income (negative) effects on demand. The positive substitution effect reflects a switch from out-of-home to in-home consumption (such as the switch from restaurants to home cooking, home delivery, and in-home entertainment). However, as incomes fall and insecurity of incomes rise, home consumption is also likely to be negatively impacted with consequent impacts on all firms.

The demand for goods and services is also affected by the nature of the measures adopted by public health representatives to limit the diffusion or aid the treatment of the disease [8]. Restrictions imposed by the EU governments cut across the drivers, structures and capacities of economies, determining the businesses and facilities that should cease and those that can continue opening or trading, as well as limitations on household and business travel. These regulatory measures effectively overturn standard market signals and profoundly affect the demand for many goods and services.

On the supply side, pandemics and their associated lockdown predominately affect the availability and productivity of labour [9] rather than land and capital as factors of production. Labour intensive businesses, or those that rely heavily upon occupations and skills deemed by governments to be non-essential, are most immediately at risk and a principal source of wider supply chain disruption, everything else being equal. In this regard, two characteristics of rural economies are pertinent. Firstly, rural areas, typically have a population distribution skewed to older people compared to urban areas [10]. Older people are more likely to require critical care and/or die as a result of a coronavirus infection [11]. UK Government advice, which mirrors that in many other European countries, is that those aged over 70 should socially isolate, making them dependent on others in rural communities to collect shopping and medical prescriptions. It follows that self-isolating and shielding behaviour will also disproportionally impact rural areas through the availability of ('grey') labour for businesses, social enterprises and volunteer work and through the impact of their reduced expenditure on goods 
and services from local businesses ('grey pound'). Secondly, as labour relocates to a home working context, this could be more difficult in those rural areas suffering from inferior access to high quality broadband [12,13]. This weakness will also affect home schooling during closures and be exacerbated by concurrent demands for limited available bandwidth (data transfer capacity) among multiple household members.

Disruption and reconfiguration of supply chains is likely to be especially pronounced for firms relying on international markets, given the interruption of port activity, flights and ferry routes. In the UK, approximately 10 percent of rural firms import or export internationally, with similar proportions of rural and urban firms exporting to the EU and non-EU [14]. In some EU countries, the dependence on exporting and reliance on imported inputs is greater [15]. As countries erect measures to prevent the spread of COVID-19, exporting is becoming more difficult, and the time taken to reach markets is increasing. Based on experiences of past pandemics, export activity will drop as supply side restrictions increase and global demand falls [16]. The UK Government's objectives of increasing exports—especially to non-EU markets, which is also an objective of the EU-will be very difficult to achieve.

Disruption or reconfiguration of businesses and their supply chains will also affect those operating in domestic markets, deemed to be 'non-essential', as well as those reliant on personal, employee or commercial travel and/or transport (e.g., educational establishments from schools to universities, hospitality and retail businesses, public transport, vehicle hire and house removal businesses, etc.). In both these situations, there are opportunities for the re-orientation of capital, skills and products to enter markets under strain from short-term supply challenges, as in the rural health care and food processing sectors, with the potential of retaining these additional supply chains and markets beyond the recovery stages.

\section{Agriculture}

The impact of the COVID-19 outbreak on farms, forestry and fisheries will be variable. Some will be less affected, where operations are deemed 'essential' and contracts for produce are already negotiated for medium- or long-term delivery. The same goes for those feeding into essential food, fish or timber processing businesses and with direct farm payments continuing. Moreover, the majority of EU farms are family farms where the workforce and capital are already on site or drawn from their immediate rural localities, with good social distancing and with many still largely producing for in-home food consumption [17]. However, some livestock sales, haulage and auction mart operations may be severely disrupted. Moreover, those supplying the hospitality sector for out-of-home food consumption, as well as those selling directly to consumers through on-farm outlets, will be directly impacted. These will need to adjust to a reconfigured food supply chain.

Overall, supermarket food supply chains have proved remarkably resilient, coping well with consumer stockpiling behaviour. In some areas, increased consumer demand allowed, in the short-term, for farms and food processors to place unsold stock and increase turnover, labour permitting. This, however, is likely to be short lived as stockpiling ceases. Some farm businesses are able to reorient their output from serving the out-of-home sector (e.g., hospitality) to in-home food consumption supply chains (e.g., supermarket-led supply chains, box schemes, or direct online sales). There is some anecdotal evidence that the crisis increased urban residents' demand for farm produce in France [18] and polling for the Food, Farming and Countryside Commission in the UK indicates that the COVID-19 outbreak led consumers to value local food more and stimulated purchases of community vegetable boxes and local farm produce [19]. However, reorientation to direct consumer sales is not always possible or can only be done with significant financial implications, particularly for small-scale niche operators [20].

The most heavily affected farms are those that are dependent on seasonal/migrant labour or sales, notably fruit and vegetable production, horticulture and garden nurseries; those which have diversified into out of the home goods and services, selling direct to the public (e.g., agri-tourism, 
visitor attractions, farm shops); and those reliant upon non-farm household income sources affected by COVID-19. In several European countries, the situation is complicated by the high proportion of seasonal and migrant farm workers who are undeclared and work in the grey and black economy [21].

In terms of communities and social distancing, there are very important mental health, wellbeing and community impacts of COVID-19. These are linked to the pervading disruption of social relations, structures and community participation, with the switch from out-of-home to in-home lifestyles and more physically isolated living [22]. Again, this effect is exacerbated for those in rural areas less able to maintain social contact online whilst social distancing and shielding. These impacts are potentially acute for those already suffering from rural vulnerability, loneliness and social isolation, and compounded further for those with poor access to high-speed broadband or mobile signal coverage. A characteristic of the pandemic has been the switch from face to face to digital connections for schooling, higher education, business meetings, health consultations, shopping and cultural events. However, this is much more problematic in localities with weak internet and mobile connections, which tend to be overwhelmingly rural, and leads to further marginalisation of rural citizens and communities. For those dependent on carers, the carers themselves may be unable to offer the fullest level of necessary support due to social distancing. Furthermore, with access to essential services already more challenging in rural areas, and with poorer service capacity and critical mass of key workers (doctors, care workers, emergency services, pharmacists, etc.), rural areas' vital services are especially vulnerable and at risk of becoming overstretched should these people fall ill, are required self-isolate or if there is a rapid increase in cases within local communities linked to their ageing demography.

There is emerging anecdotal evidence that COVID-19 is opening up new tensions within and between communities over social distancing and purchasing behaviours, including examples of 'othering' of commuters and urban visitors to the countryside over fears of disease spread and scarcity of provisions [23]. For instance, in the UK there has been widespread media coverage of roadside signs asking visitors to stay away from the Lake District and rural Wales, sometimes reinforced by police checkpoints. Visits to second homes as rural sanctuaries have been especially divisive.

Less visible in current considerations of mental and social wellbeing, but potentially as challenging in many communities, is the impact on young people. Many students and young people will have been isolated from friends and support structures by the closure of schools and colleges, transport options and meeting venues, and further frustrated in some rural areas by potentially inferior online access or mobile signals. Some will be confined to small, dispersed communities with few, or even no, similarly young residents, whilst others will be less able to share and soothe their anxieties with peers about impending examinations or transfers to higher-level schools and colleges.

Rural areas have often been at the vanguard of community and social enterprise [24,25], and COVID-19 is itself leading to the promulgation of many positive examples of community, neighbour and volunteer support. How public, private and third sectors effectively work together-and, crucially, how they work with the rural voluntary, community and social enterprise (VCSE) ecosystem-is critical to immediate emergency response and will be vital to longer-term recovery. However, whilst the VCSE sector is adept at balancing social, economic and environmental needs, it has been heavily stretched in the years leading up to the pandemic and now faces a range of challenges [26]. With social shielding of older populations, who are an important source of volunteer labour, the sector too is facing challenges linked to labour availability. Thus, while the crisis offers opportunities for rural communities to make use of and to strengthen existing volunteering and neighbourliness, a weakness of the rural social support system is its reliance on older volunteers to look out for an ageing population. There is a need for governments to view organisations in this sector in a similar light to private and public businesses and employees, providing financial support to sustain their viability. Support is especially justified, given that in many rural communities these organisations play the leading role in organising and supporting older, young and vulnerable residents. They may need to bolster younger volunteering and neighbourliness and repurpose older volunteering to fit with current restraints and the limits placed on their movement. These extra demands need external support, but the VCSE sector often 
falls between business, charity and household policy frameworks [27]. COVID-19 serves to further emphasise the imperative for community capacity building and support through the rural VCSE sector, to allow it to help individuals, households and communities during the pandemic and recovery.

\section{Gender and the Rural Economy}

The impacts of COVID-19 are experienced differently between genders. Many of the frontline occupations affected by the virus impact disproportionately on women. Teachers, carers and nurses are predominantly women. Throughout the EU, women are predominantly responsible for childcare [28] and home schooling is likely to have gendered implications within families. Female rural entrepreneurs and women who have undertaken farm diversification initiatives have often done so to fit around their other childcare and caring responsibilities [29]. Maintaining these businesses while undertaking additional COVID-19 caring roles will be a challenge. There may be gendered effects that will mean differential access to household assets that can be used to buffer the effects of the coronavirus on firms. During FMD, male-owned firms were far more likely to draw on unpaid labour of household members, and female-owned businesses were less likely to use household savings to ease cash flow or to take on additional loans or debts, in order to limit risks to families and households [1].

\section{Rural Resilience, Coping and Adaptation}

Responses to previous crises indicate that household, community and business impacts and coping responses are closely intertwined [1,5,9]. Rural business coping and adaptive responses depend on the prior availability and use of assets (financial, physical, social, human, etc.) within business households and their supporting community networks. Critically, responses also depend on the scale of any business or household reserves prior to the external shock [30,31]. Business income is only one of a package of financial strands that sustain many rural households and firms in times of crisis-waged work (casual, part-time or full-time), occupational pensions, investment income and state benefits, as well as savings, reserves and credit are also part of the mix. During FMD, this 'pluriactive' income portfolio, characteristic of many rural households, proved essential in cushioning reduced flows of income and ameliorating cash flow problems [5]. Rural economies with higher levels of self-employment, and small and micro-enterprises with limited solvency and cash reserves, are likely to be less prepared to weather the disruption caused by COVID-19.

Coping and resilience processes themselves often generate secondary social and economic consequences for household members and employees. The knock on effects of FMD on flexible rural labour was considerable but often hidden from official statistics or supports, with impacts felt through the release of casual and seasonal workers and reduced hours for retained employees $[1,5]$. COVID-19 may similarly impinge significantly, though less visibly, on those with part-time, seasonal, low income and more irregular work, as well as those who may more easily fall through the cracks in support provision. The coping strategies of rural micro-firms, moreover, depend heavily on the use of spousal and household labour on a flexible unpaid basis, with households providing vital emotional support for business owners $[1,5]$. Coping strategies also involve reductions in household consumption, investment and spending to compensate for reduced income flow from businesses to the household.

In contrast, it is also likely that COVID-19 will stimulate many examples of innovative community and business responses and adaptation across rural areas, and from which learning should be distilled. Necessity is an important driving force for rural business innovation [32]. For instance, some creative and digital businesses are taking advantage of opportunities afforded by people working from home. Some businesses are also likely to face additional demand or identify complementary or alternative products and markets, and in turn these will require innovation in their processes, goods and services. 


\section{Business Recovery Measures}

The sectoral, spatial and community impacts of COVID-19 and the measures to contain it will be significant and far-reaching. For some industries and localities, urban-driven recovery will reach into rural economies. For most rural places, the interconnected nature of rural economies will demand a cross sectoral response, with measures addressing and stimulating both demand (e.g., encouraging consumption, tapping into new markets) and supply (e.g., encouraging production) challenges. Throughout and following the pandemic, businesses will be left with an immediate legacy of debt, reduced financial reserves and investment capability, disrupted trade, delayed growth and investment, disruptions to their employee base, unsold or outdated stock and reduced marketing budgets [16]. These effects will adversely affect their ability to recover once the immediate crisis passes.

Monitoring of business impacts, resilience and recovery will need to be ongoing and long-term, as firms and social enterprises in different sectors and places are impacted and recover at different rates. Experience of FMD and the 2007-2008 financial crisis showed that for some firms and rural economies the recovery will be swift, whereas for others it will be delayed [1,2]. This pattern is likely to be repeated in the aftermath of COVID-19. Recovery and future research will also need to be mindful of the long-term trauma and consequences for communities. It will need to learn from other contexts where this has been previously explored [31] and determine how to regenerate depleted rural communities.

A starting point for economic recovery following the COVID-19 outbreak, however, is the effectiveness and equitable distribution of the current and evolving business and community support packages being enacted at regional, national and supra-national levels. It will be vital for the governments to monitor the design and delivery of such business, employment and community support interventions, for their rural relevance, uptake and impact. During FMD, when large swathes of the British countryside closed for several months as measures were taken to prevent the spread of the disease, it was apparent that many firms had not sought or obtained special assistance [1]. This included some that were severely impacted, and many were frustrated in their attempts to access aid or fell through the gaps of the support framework. On the other hand, during the 2008-2010 recession, many rural firms showed a resilience that exceeded that of many urban economies [2]. However, they then struggled to gain equitable assistance for recruiting, training and marketing due to weaknesses in support provision in their rural areas, or because recovery funds were perceived to have greater impact if oriented to city or urban locations and sectors [2,12].

Governments across Europe are enacting support packages to subsidise firms so they can retain employees, and in some cases this has been extended to self-employment. The latter is particularly important for rural economies, as self-employment is proportionally more prevalent than in urban areas [33]. However, supporting large numbers of small-scale, self-employed businesses (including those recently established or for whom self-employment is a second job) and their access to small business grants (for those that do not have premises or employ staff to meet centrally-defined eligibility criteria), presents a particular ongoing challenge [34].

Further potential weaknesses in the COVID-19 support measures remain in relation to its delivery in rural areas and support of cash flow. In the UK, over-demand and under-capacity for online registration to access social security and tax offices [35] is a deterrent, especially for applicants who find themselves in weaker broadband locations and are therefore unable to access information, advice and application processes. In normal conditions, rural business applications for cash flow finance tend to be more targeted to, and reliant on, credit cards and overdrafts as opposed to loans and bank finance, especially for microbusinesses $[36,37]$. Decisions pertaining to payment holidays or help with late or non-payments for such funds reside with the banks, and their response should therefore also be monitored for rural reach and relevance. Additionally, seasonality of cash flow can determine the difference between success or closure, so timeliness as well as appropriateness of external help is needed and should be monitored. Support may also be lacking or dispersed for individual business or business sector support in order to encourage and support re-tooling and re-directing supply chains or 
mechanisms, as well as to encourage new place- or sector-based initiatives to collate, co-ordinate and promote 'non-essential' businesses to market their goods and services.

\section{Long-Term Effects and Research Agenda}

During the recovery phase, actions will be required to reset economies and address impacts on rural communities. The impact of COVID-19 on public finances, personal freedoms, international trade and public debates will be substantial [38], with changes at national, European and global levels affecting rural economies. One long-term ramification of COVID-19 may be the acceleration of firms substituting capital for labour in order to reduce vulnerability to future pandemics (particularly in an environment where the costs of capital investment through low interest rates and government loans will be low). This may affect things like social care, where there may be a further push to develop technological aids to help older people stay in their homes and remain independent rather than enter residential care or require daily care visits. It is possible that COVID-19 will make rural areas more attractive for the future, given the space they afford. This raises questions over trends to centralise health care and other services.

An open question concerns the extent to which changes in household, business or supply chain behaviours brought about by the pandemic will return to their original state once it has run its course. The latter is unlikely to be quick, with some restrictions, particularly those relating to the vulnerable citizens, likely to persist for several months, if not years. New behaviours induced by the outbreak will have a considerable period of time to become habitual. So while flights will resume, cinemas reopen, and commuting return, a proportion of activity may not recover; for example, some people will continue to work from home, get out of the habit of going to the cinema, or decide some work trips are expendable. Some businesses will not be able to raise capital, recruit employees or find new owners to resurrect businesses. This begs several research questions:

- Will changes from face to face to digital connections in education, health, shopping, business and culture, induced by the pandemic, persist, and what are the implications of this for rural communities characterised by weak internet connectivity?

- Will preferences for and the pace of rural remote working and living accelerate as businesses and employees realise that in many instances they can work remotely, away from the crowds?

- What is the effectiveness of current and evolving business and community support measures, and to what extent is the distribution of funding equitable across localities and communities?

- Will the pandemic lead to a longer-term increase in demand for local foods and shorter supply chains? Will there be an increase in households producing their own home-grown food?

- What are the implications of the pandemic for the rural VCSE sector, and what scope is there to explore alternative organisational structures and enterprises that align with social objectives?

- What future demographics and population movements may unfold?

- With the pandemic exacerbating some existing tensions between supra-national, national and regional/local governments regarding authority for policy making and delivery, as well as distribution of budgets, will it induce longer-term changes to governance arrangements, and what are the implications for rural areas?

- How might the pandemic lead to innovation in service provision, digital technology, energy use and production?

- What might be the environmental impacts and opportunities of these potential longer-term effects for rural areas?

Answering these questions about long-run implications, some of which may be desirable and others less so, will be an important focus for future research, policy analysis and much needed rural foresight. 
Author Contributions: Conceptualization, J.P., M.G. and R.T.; investigation, J.P., M.G., R.T., M.S., K.A.-M., F.A., P.C., C.H., S.M., R.M., D.S.-M., R.N., L.P., F.R., S.S.; writing-original draft preparation, J.P., M.G., R.T., M.S., K.A.-M., F.A., P.C., C.H., S.M., R.M., D.S.-M., R.N., L.P., F.R., S.S.; writing-review and editing, J.P., M.G. and D.S.-M.; project administration, J.P. and M.G.; funding acquisition, J.P. and M.G. All authors have read and agreed to the published version of the manuscript.

Funding: This research was funded by the Economic and Social Research Council (ES/M500513/1 and ES/S007024) and the ERDF Interreg Europe project INNOGROW (Regional Policies for Innovation Driven Competitiveness and Growth of rural SMEs).

Conflicts of Interest: The authors declare no conflict of interest.

\section{References}

1. Phillipson, J.; Bennett, K.; Lowe, P.; Raley, M. Adaptive responses and asset strategies: The experience of rural micro-firms and Foot and Mouth Disease. J. Rural Stud. 2004, 20, 227-243. [CrossRef]

2. Commission for Rural Communities. From Credit Crunch to Recovery: The Impact of Recession in Rural England; Commission for Rural Communities: Gloucester, UK, 2010.

3. Newbery, R.; Bosworth, G. Home-based business sectors in the rural economy. Soc. Bus. Rev. 2010, 5, $183-197$. [CrossRef]

4. Dissart, J.-C.; Aubert, F.; Truchet, S. An Estimation of Tourism Dependence in French Rural Areas. In Advances in Tourism Economics: New Developments; Matias, Á., Nijkamp, P., Sarmento, M., Eds.; Physica-Verlag HD: Heidelberg, Germany, 2009; pp. 273-294. [CrossRef]

5. Bennett, K.; Phillipson, J. A Plague Upon their Houses: Revelations of the Foot and Mouth Disease Epidemic for Business Households. Sociol. Rural. 2004, 44, 261-284. [CrossRef]

6. Steiner, A.; Atterton, J. Exploring the contribution of rural enterprises to local resilience. J. Rural Stud. 2015, 40, 30-45. [CrossRef]

7. Shucksmith, M. Future Directions in Rural Development? Carnegie UK Trust: Dunfermline, UK, 2012.

8. Ma, C.; Rogers, J.H.; Zhou, S. Global Economic and Financial Effects of 21st Century Pandemics and Epidemics; Federal Reserve Board: Washington, DC, USA, 2020.

9. Karlsson, M.; Nilsson, T.; Pichler, S. The impact of the 1918 Spanish flu epidemic on economic performance in Sweden: An investigation into the consequences of an extraordinary mortality shock. J. Health Econ. 2014, 36, 1-19. [CrossRef] [PubMed]

10. Eurostat. Statistics on Rural Areas in the EU Eurostat; Eurostat: Brussels, Belgium, 2017.

11. Wu, Z.; McGoogan, J.M. Characteristics of and Important Lessons from the Coronavirus Disease 2019 (COVID-19) Outbreak in China: Summary of a Report of 72314 Cases From the Chinese Center for Disease Control and Prevention. JAMA 2020, 323, 1239-1242. [CrossRef] [PubMed]

12. Commission for Rural Communities. Rural Micro-Businesses: What Makes Some Thrive in a Challenging Economic Climate? Commission for Rural Communities: Gloucester, UK, 2013.

13. OFCOM. Broadband Speeds; OFCOM: London, UK, 2017.

14. Phillipson, J.; Tiwasing, P.; Gorton, M.; Maioli, S.; Newbery, R.; Turner, R. Shining a spotlight on small rural businesses: How does their performance compare with urban? J. Rural Stud. 2019, 68, 230-239. [CrossRef]

15. Schmied, D. Winning and Losing: The Changing Geography of Europe's Rural Areas; Ashgate Publishing Ltd.: Aldershot, UK, 2005; pp. xiii + 307 pp.

16. McKibbin, W.J.; Fernando, R. The Global Macroeconomic Impacts of COVID-19: Seven Scenarios; Australian National University: Canberra, Australia, 2020.

17. European Commission. Structure and Dynamics of EU Farms: Changes, Trends and Policy Relevance; DG Agriculture: Brussels, Belgium, 2013.

18. Ouest France. Coronavirus. Vire Normandie: À la Ferme d'Uo, le Confinement n'Empêche pas l'Affinage. Available online: https://www.ouest-france.fr/sante/virus/coronavirus/coronavirus-vire-normandie-la-ferm e-d-uo-le-confinement-n-empeche-pas-1-affinage-6809556 (accessed on 24 April 2020).

19. FFCC. The Impact of Coronavirus on Food Behaviours and Attitudes; Food, Farming and Countryside Commission: London, UK, 2020.

20. Hingley, M.K. Power to all our friends? Living with imbalance in supplier-retailer relationships. Ind. Mark. Manag. 2005, 34, 848-858. [CrossRef] 
21. Erizanu, P. Stranded or Shunned: Europe's Migrant Workers Caught in No-Man's Land. The Guardian. 16 April 2020. Available online: https:/www.theguardian.com/world/2020/apr/16/stranded-or-shunned-eu ropes-migrant-workers-caught-in-no-mans-land (accessed on 17 April 2020).

22. World Health Organization. Mental Health and Psychosocial Considerations during the COVID-19 Outbreak, 18 March 2020; World Health Organization: Geneva, Switzerland, 2020.

23. Dixon, H. Rural residents tell 'Covidiot' visitors to go home, with parks and beauty spots packed: Backlash as people ignore social distancing rules and fail to stay two metres apart. The Telegraph. 23 March 2020.

24. Steinerowski, A.A.; Steinerowska-Streb, I. Can social enterprise contribute to creating sustainable rural communities? Using the lens of structuration theory to analyse the emergence of rural social enterprise. Local Econ. 2012, 27, 167-182. [CrossRef]

25. Townsend, L.; Wallace, C.; Smart, A.; Norman, T. Building Virtual Bridges: How Rural Micro-Enterprises Develop Social Capital in Online and Face-to-Face Settings. Sociol. Rural. 2016, 56, 29-47. [CrossRef]

26. Milbourne, L.; Cushman, M. Complying, Transforming or Resisting in the New Austerity? Realigning Social Welfare and Independent Action among English Voluntary Organisations. J. Soc. Policy 2015, 44, 463-485. [CrossRef]

27. Agapitova, N.; Sanchez, B.; Tinsley, E. Government Support to the Social Enterprise Sector: Comparative Review of Policy Frameworks and Tools; The World Bank: Washington, DC, USA, 2017.

28. Erhel, C.; Guergoat-Larivière, M. Labor Market Regimes, Family Policies, and Women's Behavior in the EU. Fem. Econ. 2013, 19, 76-109. [CrossRef]

29. Shortall, S.; Sutherland, L.; McKee, A.; Hopkins, J. Women in Farming and the Agriculture Sector; Scottish Government: Edinburgh, Scotland, 2017.

30. Moser, C.O. Confronting Crisis; The World Bank: Washington, DC, USA, 1996. [CrossRef]

31. Kitching, J.; Blackburn, R.; Smallbone, D.; Dixon, S. Business Strategies and Performance During Difficult Economic Conditions; Kingston University: London, UK, 2009.

32. North, D.; Smallbone, D. The Innovativeness and Growth of Rural SMEs during the 1990s. Reg. Stud. 2000, 34, 145-157. [CrossRef]

33. Faggio, G.; Silva, O. Self-employment and entrepreneurship in urban and rural labour markets. J. Urban Econ. 2014, 84, 67-85. [CrossRef]

34. Rouse, J.; Hart, M.; Prashar, N.; Kumar, A. Covid-19: Critique and Proposals to Develop More Comprehensive and Inclusive Support for the Self-Employed. 2020. Available online: https://www.enterpriseresearch.ac.uk/wp-content/uploads/2020/04/ERC-ResReport-Covid-19-D eveloping-More-Comprehensive-and-Inclusive-Policy-for-the-Self-Employed_final.pdf (accessed on 24 April 2020).

35. Proctor, K. Almost 500,000 People in UK Apply for Universal Credit in Nine Days. The Guardian. 25 March 2020. Available online: https://www.theguardian.com/world/2020/mar/25/almost-500000-people-in-uk-apply-for -universal-credit-in-nine-days (accessed on 3 April 2020).

36. Robinson, S.; Finley, J.T. Small business owners and credit cards: An analysis by gender and location. Acad. Entrep. J. 2007, 13, 97-107.

37. Kneiding, C. Financing Small Businesses in Western Europe-A Micro-Level and an Institutional Perspective. Ph.D. Thesis, Wirtschaftswissenschaftliche Fakultät, Universität Frankfurt (Oder), Frankfurt (Oder), Germany, 2007.

38. Powell, J. The State Transformed: Coronavirus Will Change the British State in Ten Crucial Ways. New Statesman. 25 March 2020. Available online: https://www.newstatesman.com/politics/health/202 0/03/state-transformed-coronavirus-will-change-british-state-ten-crucial-ways (accessed on 25 April 2020).

C 2020 by the authors. Licensee MDPI, Basel, Switzerland. This article is an open access article distributed under the terms and conditions of the Creative Commons Attribution (CC BY) license (http://creativecommons.org/licenses/by/4.0/). 